\title{
PENGARUH PEMBELAJARAN KOOPERATIF TIPE TEAMS- GAMES- TOURNAMENT (TGT) DAN METODE EKSPOSITORI TERHADAP HASIL BELAJAR PKn SISWA KELAS XI MAN TEMANGGUNG SEMESTER GANJIL TAHUN PELAJARAN 2012/2013
}

\author{
Setyorini \\ Alumni Program Studi S1 PPKn \\ FKIP - Universitas Kristen Satya Wacana \\ Bambang S Sulasmono \\ Program Studi S1 PPKn \\ FKIP - Universitas Kristen Satya Wacana \\ Henny Dewi Koeswanti \\ Program Studi S1 PPKn \\ FKIP - Universitas Kristen Satya Wacana
}

\begin{abstract}
ABSTRAK
Tujuan penelitian ini adalah untuk mendiskripsikan ada tidaknya perbedaan Pengaruh Signifikan Pembelajaran Kooperatif Tipe Teams-Games-Tournament (TGT) dan Metode Ekspositori Terhadap Hasil Belajar PKn Siswa Kelas XI Madrasah Aliyah Negeri Temanggung Semester Ganjil TahunPelajaran 2012/ 2013.

Desain penelitian yang digunakan adalah "randomized postes only control group design". Populasi dalam penelitian ini adalah siswa kelas XI MAN Temanggung tahun ajaran 2012/2013 yang terdiri dari 9 (Sembilan) kelas yaitu XI IPS 1, XI IPS 2, XI IPS3, XI IPA 1,XI IPA 2, XI IPA 3, XI IPA 4, XI Bahasa dan XI Agama. Sampel penelitian ini adalah kelas XI IPS-1 sebagai kelas kontrol dan kelas IX IPS-3 sebagai kelas eksperimen. Sampel diambil secara random. Teknik pengumpulan data menggunakan tes dan pengujian hipotesis menggunakan bantuan program SPSS for window version 18.

Hasil uji validitas instrumen dari 58 soal terdapat 37 soal yang valid dan 21 buah tidak valid, sementara reliabilitasnya 0,743 . Hasil uji normalitas untuk kelas eksperimen sebesar 0,052 dan kelas kontrol sebesar 0,187 lebih besar dari nilai signifikan 0,05 sehingga disrtibusi data dikatakan normal. Sedangkan uji homogenitas sebesar 0,392 lebih besar dari nilai signifikan 0,05 sehingga kelas kontol dan kelas eksperimen mempunyai varian yang sama atau homogen. Hasil uji hipotesis penelitian diperoleh pada $\alpha$ $=5 \%: 2=2,5 \%$ (uji 2 tailed) dengan derajat kebebasan (df) sebesar $69(\mathrm{df}=71-2)$, nilai t hitung $>$ $\mathrm{t}$ tabel $(2,774>1,995)$ dan bila dilihat dari signifikasinya $(0,008<0,05)$ maka diartikan bahwa $\mathrm{H}_{0}$ ditolak dan $\mathrm{H}_{1}$ diterima yang menyatakan bahwa ada perbedaan pengaruh yang signifikan antara pembelajaran kooperatif Team-Games-Tournament (TGT) dengan metode ekpositori terhadap hasil belajar Pendidikan Kewarganegaraan (PKn) kelas XI MAN Temanggung semester ganjil tahun pelajaran 2012/2013. Adapun saran penulis berkaitan dengan pembelajaran Pendidikan Kewarganegaraan di tingkat MAatau SMAdapat digunakan pembelajaran kooperatif tipe TGT karena terbukti mampu meningkatkan hasil belajar PKn, oleh karena itu guru harus mempertimbangkan penggunaan metode ini dalam proses pembelajaran PKn.
\end{abstract}

Kata Kunci: Teams-Games-Tournament, metode ekpositori dan hasil belajar 


\section{PENDAHULUAN}

Menurut Undang-Undang Pendidikan Nasional No.20 tahun 2003 pasal 3, tujuan pendidikan nasional adalah berkembangnya potensi peserta didik agar menjadi manusia yang beriman dan bertaqwa kepada Tuhan Yang Maha Esa, berahlak mulia, sehat, berilmu, cakap, kreatif, mandiri, dan menjadi warga negara yang demokratis serta bertanggung jawab. Tujuan pendidikan nasional tersebut dicapai melalui pendidikan formal dan non formal. Salah satu mata pelajaran yang disajikan di sekolah adalah pendidikan kewarganegaraan. Pendidikan kewarganegaraan adalah mata pelajaran yang memfokuskan pada pembentukan warganegara yang memahami dan mampu melaksanakan hak dan kewajibannya untuk menjadi warga negara Indonesia yang cerdas, terampil dan berkarakter yang diamanatkan oleh Pancasila dan UUD 1945 (Peraturan Pemerintah No. 19 Tahun 2005).

Dalam rangka mencapai tujuan pendidikan nasional dan sekaligus memajukan mutu pendidikan, pemerintah menerapkan berbagai kebijakan dengan menetapkan 8 Standar Nasional Pendidikan Indonesia yaitu standar kompetensi lulusan, standar isi yang mencakup kerangka dasar, struktur kurikulum, beban belajar, kurikulum tingkat satuan pendidikan dan kalender pendidikan, standar proses, standar pendidikan dan tenaga kependidikan, standar sarana dan prasarana, standar pengelolaan pendidikan, standar pembiayaan pendidikan serta standar penilaian pendidikan.Dalam upaya mewujudkan standar proses maka para guru di Indonesia di dorong untuk memperbaiki kinerja terutama dengan penggunaan metode-metode yang tepat dalam proses pembelajaran.

Selama ini para ahli telah memperkenalkan proses pembelajaran yang dilihat dari sudut pandang baru yaitu pembelajaran yang inovatif. Dalam pembelajaran inovatif terdapat beberapa macam pembelajaran diantaranya (Sanjaya, 2012): 1) Active Learning, 2) PAKEM, 3) Problem Based Learning, dan 4) Cooperative Learning

Salah satu pembelajaran kooperatif adalah Team-Games-Tournament (TGT). Menurut Robert
E. Slavin (2008), secara umum TGT sama dengan Student Team-Achievement Division (STAD) kecuali satu hal: TGT menggunakan turnamen akademik, dan menggunakan kuis-kuis serta sistem skor kemajuan individu, para siswa berlomba sebagai wakil tim mereka dengan anggota tim lain yang kinerja akademiknya setara dengan mereka.

Perlunya pembelajaran inovatif diharapkan dapat menggantikan pembelajaran yang menggunakan metode ekspositori atau ceramah yang masih digunakan guru dalam proses pembelajaran. Ekspositori adalah metode yang menekankan pada proses penyampaian materi secara verbal dari seorang guru kepada sekelompok siswa dengan maksud agar siswa dapat menguasai materi pembelajaran secara optimal (Sanjaya, 2012).

Guna mengetahui perbedaan pengaruh antara kedua metode di atas terhadap hasil belajar PKn siswa, maka penelitian ini memilih berjudul: Perbedaan Pengaruh Pembelajaran Kooperatif Tipe Teams- Games-Tournament (TGT) Dan Metode Ekspositori Terhadap Hasil Belajar Pkn Siswa Kelas XI Madrasah Aliyah Negeri Temanggung Semester Ganjil Tahun Pelajaran 2012/2013.

Bertitik tolak dari latar belakang di atas maka penulis merumuskan permasalahan penelitian ini adalah: "adakah perbedaan pengaruh yang signifikan antara pembelajaran kooperatif TeamGames-Tournament (TGT) dan metode ekspositori terhadap hasil belajar PKn kelas XI IPS MAN Temanggung Semester Ganjil Tahun Pelajaran 2012 / 2013 ?".

Adapun tujuan penelitian ini adalah: mendiskripsikan perbedaan pengaruh yang signifikan antara pembelajaran kooperatif TeamGames-Tournament (TGT) dan metode ekspositori terhadap hasil belajar PKn kelas XI MAN Temanggung Semester Ganjil Tahun Pelajaran 2012/2013.

\section{Team-Games-Tournament (TGT)}

Team-Games-Tournament (TGT) merupakan bagian dari pembelajaran coopertife learning. Robert E. Salvin (2008) mengutarakan, secara 
umum TGT sama dengan STAD (student team achievement division) kecuali satu hal, yaitu TGT menggunakan turnamen akademik dan menggunakan kuis-kuis serta sistem skor kemajuan individu di mana para siswa berlomba sebagai wakil tim mereka dengan anggota tim lain yang kinerja akademiknya setara dengan mereka. Aktivitas belajar dengan permainan yang dirancang dalam pembelajaran kooperatif TGT memungkinkan siswa dapat rileks di samping menumbuhkan tanggung jawab, kerja sama, persaingan sehat dan keterlibatan belajar (Kiranawati, 2007).

Dalam pelaksanakan pembelajaran kooperatif tipe TGT, terdapat lima komponen yang harus diperhatikan (Slavin, 2008) sebagai berikut: 1) Penyajian kelas, 2) Belajar tim, 3). Persiapan permainan/pertandingan, 4) Permainan/pertandingan, 5) Rekognisi (penghargaan)tim. Dengan demikian apabila komponen-komponen tersebut dilaksanakan secara sistematis maka akan terjadi kompetisi dalam hal akademik serta siswa berlomba untuk memperoleh hasil belajar yang optimal.Langkah-langkah dan aktifitas pembelajaran kooperatif tipe Teams-Games Tournament (TGT) sebagai berikut: (1) Pembelajaran diawali dengan memberikan pelajaran (tahap penyajian kelas) dan belajar dalam kelompok /Tim yang beranggotakan 4-5 orang, (2) Kegiatan dalam turnamen adalah persaingan pada meja turnamen dari 4-5 siswa dengan kemampuan setara, (3) Apabiala permainan sudah berakhir, para siswa mencatat/merekap total skor yang telah mereka dapatkan dan (4) Setelah siswa dalam kelompok merekap masing-masing skor yang diperoleh pada lembar penilaian guru mengumpulkan lembar tersebut kemudian mengemukakan perolehan skor untuk setiap kelompok dan memberikan penghargaan pada kelompok dan individu yang memperoleh skor tertinggi.

\section{Metode Ekspositori}

Ekspositori adalah metode yang menekankan pada proses penyampaian materi secara verbal dari seorang guru kepada sekelompok siswa dengan maksud agar siswa dapat menguasai materi pembelajaran secara optimal (Wina Sanjaya, 2012). Metode ekpositori dikenal dengan istilah pembelajaran langsung (direct instruction). Metode ekpositori hakikatnya sama dengan metode ceramah dalam hal terpusatnya kegiatan kepada guru sebagai pemberi informasi (Sagala, 2010 dalam Nurwulan, 2012). Langkah-langkah penerapan metode ekspositori (Wina Sanjaya, 2012): (1) Persiapan, (2) Penyajian, (3) Menghubungkan, (4) Menyimpulkan dan (5) Penerapan.

Dalam pelaksanaan metode ekspositori, siswa diharapkan dapat menangkap informasi yang telah disampaikan oleh guru serta dapat mengungkapkan kembali apa yang telah dimilikinya melalui respon yang telah diberikan pada saat diberikan pertanyaan oleh guru (Anitah dalam Afriyani, 2011). Sebelum menerapkan metode ekspositori dalam proses pembelajaran, terdapat prinsip-prinsip ekspositori yang harus diperhatikan dalam pelaksanaanya (Wina Sanjaya, 2012) yaitu 1) Berorientasi pada tujuan, 2) Prinsip komunikasi, 3) Prinsip kesiapan, 4) Prinsip berkelanjutan.

\section{Hasil Belajar}

Hasil belajar termasuk dalam kelompok atribut kognitif "respons", hasil pengukurannya tergolong pendapat (judgment) yaitu respon yang dapat dinyatakan benar atau salah (Suryabrata, 2002). Menurut Mulyono (2003) hasil belajar adalah kemampuan yang diperoleh anak setelah melalui kegiatan belajar. Hal senada juga disampaikan oleh Nana Sudjana (2010) mengemukakan bahwa belajar dan mengajar sebagai aktifitas utama di sekolah yang meliputi tiga unsur yaitu tujuan pembelajaran, pengalaman belajar mengajar dan hasil belajar.

Berdasarkan beberapa pendapat di atas tentang pengertian hasil belajar, maka dapat disimpulkan bahwa hasil belajar merupakan proses kemampuan yang diproleh siswa setelah melalui kegiatan belajar dalam waktu tertentu. Selain itu dapat dipahami bahwa penialaian hasil belajar terhadap siswa untuk mengetahui sejauh mana siswa memahami tentang materi yang telah diajarkan. 
Hasil belajar tersebut dapat diamati dan diukur dalam bentuk perubahan pengetahuan, sikap dan keterampilan untuk menentukan tercapainya atau tidaknya tujuan pembelajaran yang dilakukan.

\section{Pendidikan Kewarganegaraan}

Pendidikan kewarganegaraan adalah mata pelajaran yang memfokuskan pada pembentukan warganegara yang memahami dan mampu melaksanakan hak dan kewajibannya untuk menjadi warga negara Indonesia yang cerdas terampil dan karakter yang diamanatkan oleh Pancasila dan UUD 1945 (Peraturan Pemerintah No. 19 Tahun 2005).

Dalam standar kompetensi kurikulun 2004 (Dasim Budiansyah, 2007) pendidikan kewarganegraan adalah merupakan mata pelajaran yang memfokuskan pada pembentukan diri yang beragam dari segi agama, sosial-kultural, bahasa, usia, dan suku-suku bangsa yang menjadi warga negara Indonesia yang cerdas, terampil serta berkarakter yang dilandasi oleh Pancasila dan UUD 1945.

Hal senada juga disampaikan oleh Ahmad Haris (2009) bahwa pendidikan kewarganegaraan adalah mata pelajaran yang digunakan sebagai wahana untuk mengembangkan dan melestarikan nilai luhur dan moral yang berakar pada budaya Indonesia, serta diharapkan dapat diwujudkan dalam bentuk perilaku dalam kehidupan seharihari peserta didik, baik sebagai individu maupun sebagai anggota masyarakat dan mahkluk ciptaan Tuhan Yang Maha Esa.

Berdasarkan pendapat di atas maka dapat dipahami bahwa pendidikan kewarganegaraan adalah mata pelajaran pembentukan diri, mengembangkan dan melestarikan nilai luhur dan moral untuk menjadi warganegara Indonesia yang cerdas, terampil serta berkarakter yang dilandasi oleh Pancasila dan UUD 1945.

\section{METODE PENELITIAN}

Penelitian ini menggunakan metode penelitian eksperimen dengan desain penelitian yang digunakan adalah randomized postest only control group design, dalam model ini terdapat kelompok kontrol yang tidak diberi perlakuan khusus tapi perlakuan seperti biasa sedangkan kelompok eksperimen diberi perlakuan khusus (Nana Syaodih, 2007). Teknik pengumpulan data dilakukan dengan mengunakan tes. Di mana tes dilakukan setelah siswa mendapat perlakuan dengan model TGT dan Ekspositori. Berdasarkan data dari hasil tes tersebut maka akan diperoleh data sebagai hasil belajar siswa.

\section{HASIL PENELITIAN DAN PEMBAHASAN}

Untuk melihat normalitas di kelas eksperimen dan kelas kontrol disajikan pada tabel 1.

Data pada tabel 1 tersebut dapat dikatakan normal apabila nilai signifikasinya lebih dari 0,05 (signifikasi > 0,005). Berdasarkan data dalam kolom Kolmogorov-Smirnov dapat diketahui nilai signifikasi kelas Kontrol sebesar 0,052 atau lebih besar dari 0,05 (0,052>0,05), maka signifikasi normal dan nilai signifikasi kelas eksperimen 0,187 atau lebih besar dari 0,05 $(0,187>0,05)$. Sehingga dapat disimpulkan bahwa distribusi data kelas kontrol dan kelas eksperimen dikatakan normal.

Tabel 1 Hasil Belajar PKn Kelas XI MAN TemanggungTahun 2012/2013

Tests of Normality

\begin{tabular}{lrrrrrrr}
\hline & \multicolumn{3}{c}{ Kolmogorov-Smirnov $^{\text {a }}$} & \multicolumn{3}{c}{ Shapiro-Wilk } \\
\cline { 2 - 8 } & Statistic & Df & \multicolumn{1}{c}{ Sig. } & Statistic & Df & \multicolumn{1}{c}{ Sig. } \\
\cline { 2 - 8 } kelas_kontrol & .147 & 35 & .052 & .945 & 35 & .079 \\
kelas_eksperimen & .125 & 35 & .187 & .894 & 35 & .003 \\
\hline a. Lilliefors Significance Correction & & & & & & &
\end{tabular}


Berikut ini tabel hasil uji nilai homogenitas:

Tabel 2 Hasil Belajar PKn Kelas XI MAN Temanggung Tahun 2012/2013

\begin{tabular}{|c|c|c|c|c|c|}
\hline \multicolumn{6}{|c|}{ Test of Homogeneity of Variance } \\
\hline & & Levene Statistic & df1 & df2 & Sig. \\
\hline \multirow{4}{*}{$\begin{array}{l}\text { hasil_ } \\
\text { belajar }\end{array}$} & Based on Mean & .742 & 1 & 69 & .392 \\
\hline & Based on Median & .448 & 1 & 69 & .506 \\
\hline & $\begin{array}{l}\text { Based on Median and with } \\
\text { adjusted df }\end{array}$ & .448 & 1 & 63.093 & .506 \\
\hline & Based on trimmed mean & .645 & 1 & 69 & .425 \\
\hline
\end{tabular}

Berdasarkan tabel 2, pada baris Based on Mean kolom signifikasi diketahui bahwa nilai signifikasi data penelitian sebesar 0,392. Oleh karena itu, data dikatakan homogeny apabila nilai signifikasinya lebih dari 0,05 (signifikasi > 0,05), maka nilai signifikasinya sebesar 0,392 yang berarti nilai signifikasinya lebih besar dari 0,05 $(0,392>0,05)$ sehingga dapat disimpulkan bahwa antara kelas eksperimen dan kelas kontrol mempunyai variasi yang sama atau mempunyai hubungan yang homogen.

Hasil uji Independent Samples T-test, disajikan dalam tabel 3 berikut ini:
$\mathrm{H}_{0}$ dapat dilakukan berdasarkan pada nilai signifikan (probabilitas) yaitu jika signifikasi lebih dari 0,05 (signifikasi > 0,05) maka $\mathrm{H}_{0}$ diterima dan jika signifikasi kurang dari 0,05 (signifikasi < 0,05) maka $\mathrm{H}_{0}$ ditolak.

Berdasarkan hasil uji Independent Samples T-test yang dapat dilihat pada kolom $t$-test for Equality of Means diperoleh koefisien $\mathrm{t}$ hitung sebesar 2,774 dan nilai signifikasi sebesar 0,008. Sementara skot $\mathrm{t}$ tabel dilihat berdasarkan distribusi t yang dicari pada $\alpha=5 \%: 2=2,5 \%$ (uji 2 tailed) dengan derajad kebebasan (df) sebesar 69 $(\mathrm{df}=71-2)$. Berdasarkan hasil derajad kebebasan yang dilihat pada t tabel diperoleh nilai sebesar

Tabel 3 Hasil Analisis Uji Independent Sample T-Tes Hasil Belajar PKn Kelas XI MAN Temanggung tahun 2012/2013

\begin{tabular}{|c|c|c|c|c|}
\hline \multicolumn{5}{|c|}{ Independent Samples Test } \\
\hline & & & \multicolumn{2}{|c|}{ kelas_eksperimen } \\
\hline & & & $\begin{array}{c}\text { Equal } \\
\text { variances } \\
\text { assumed }\end{array}$ & $\begin{array}{l}\text { Equal variances } \\
\text { not assumed }\end{array}$ \\
\hline \multirow{8}{*}{$\begin{array}{l}\text { Levene's Test for } \\
\text { Equality of Variances } \\
\text { t-test for Equality of } \\
\text { Means }\end{array}$} & & & 1.945 & \\
\hline & Sig. & & .168 & \\
\hline & $\mathrm{T}$ & & 2.744 & 2.754 \\
\hline & Df & & 69 & 65.985 \\
\hline & Sig. (2-tailed) & & .008 & .008 \\
\hline & Mean Difference & & 7.608 & 7.608 \\
\hline & Std. Error Difference & & 2.773 & 2.763 \\
\hline & $\begin{array}{l}95 \% \text { Confidence Interval of } \\
\text { the Difference }\end{array}$ & Lower & 2.077 & 2.091 \\
\hline
\end{tabular}

Dasar pengambilan kesimpulan data uji hipotesis ini adalah kriteria Indpendent Samples T-Test yaitu $\mathrm{H}_{0}$ di terima jika-t lebih kecil atau sama dengan $t$ hitung lebih kecil atau sama dengan t tabel (-tabel d" t hitung d" $t$ tabel) dan $\mathrm{H}_{0}$ ditolak jika-t hitung lebih kecil dibandingkan - $t$ tabel atau thitung lebih besar dibandingkan $t$ tabel (-t hitung $<-t$ tabel atau $t$ hitung > t tabel). Untuk menguji
1,995. Maka dapat diketahui bahwa nilai t hitung $>$ t tabel $(2,774>1,995)$ dan bila dilihat dari signifikasinya $(0,008<0,05)$ maka diartikan bahwa $\mathrm{H}_{0}$ ditolak.

Oleh karena $\mathrm{H}_{0}$ ditolak berdasarkan pada nilai $t$ hitung $>\mathrm{t}$ tabel $(2,774>1,995)$ dan signifikasinya $(0,008<0,05)$, maka $\mathrm{H}_{1}$ yang menya- 
takan bahwa ada perbedaan pengaruh yang signifikan antara pembelajaran kooperatif TGT dengan pembelajaran ekspositori terhadap hasil belajar Pendidikan Kewarganegaraan (PKn) kelas XI MAN Temanggung Semester Ganjil Tahun Pelajaran 2012/2013 diterima.

\section{PEMBAHASAN}

Berdasarkan hasil uji Independent Samples T-Test di atas menunjukkan bahwa terdapat perbedaan antara pengaruh yang signifikan pembelajaran kooperatif Team-Games-Tournament (TGT) dan metode ekspositori terhadap hasil belajar Pendidikan Kewarganegaraan (PKn) kelas XI MAN Temanggung. Secara teori metode TGT belum ada yang menyatakan bahwa TGT berpotensi meningkatkan hasil belajar, namun sebuah teori menyatakan bahwa TGT meningkatkan pemahaman terhadap pokok bahasan yang dipelajari, (Taniredja, dkk., 2011) dan dalam penelitian ini membuktikan TGT meningkatkan hasil belajar PKn di MAN Temanggung.

TGT merupakan bagian dari pembelajaran kooperatif yang secara umum TGT sama dengan STAD (Student Team Achievement Division) kecuali salah satu hal, TGT menggunakan turnamen akademik dan menggunakan kuis-kuis serta sistem skor kemajuan individu di mana para siswa berlomba sebagai wakil tim mereka dengan anggota tim lain yang kinerja akademiknya setara dengan mereka (Salvin, 2008).

Dalam penelitian ini pada awal proses pembelajaran guru menyampaikan tujuan, atau kegiatan yang harus dilakukan siswa, dan memberikan motivasi kepada siswa, selanjutnya guru mempersiapkan permainan yang disusun dan yang telah dirancang. Dalam kegiatan turnamen terjadi beberapa kendala yaitu terdapat beberapa kelompok yang belum paham perputaran mainan dan terdapat kelompok yang kesulitan dalam pengisian lembar kerja kelompok. Namun semua itu, dapat diatasi oleh guru sehingga turnamen dapat berjalan dengan baik. Setelah turnamen selesai, guru merekap hasil skor masing-masing kelompok, dan mengumumkan perolehan, guru memberikan penghargaan pada kelompok dan individu yang memperoleh skor tertinggi.

Hasil penelitian ini hampir senada dengan penelitian yang dilakukan oleh Winarsi tentang "Peningkatan Prestasi Belajar Siswa dalam Pembelajaran Matematika melalui Pembelajaran Kooperatif Learning tipe Teams-Games-Tournament (TGT) di Kelas V Sekolah Dasar Negeri 8 Pondok Kelapa". Dalam penelitiannya, Winarsi menyimpulkan bahwa penerapan pembelajaran kooperatif learning tipe Teams-Games-Tournament (TGT) meningkatkan kualitas proses dan prestasi belajar Matematika siswa kelas V.

Adapun faktor yang mempengaruhi keberhasilan TGT di MAN Temanggung diantaranya: merupakan proses pembelajaran yang baru bagi siswa sehingga siswa ingin mengetahui lebih lanjut dan antusisas mengikuti proses pembelajaran menggunakan TGT dari awal sanpai akhir dengan baik. Di samping itu kelas yang digunakan dalam penelitian ini juga bukan kelas besar sehingga memudahkan guru dalam proses pembelajaran.

Berdasarkan penjelasan di atas dapat disimpulkan bahwa terdapat perbedaan pengaruh yang signifikan antara pembelajaran kooperatif TeamGames-Tournament (TGT) dengan pembelajaran ekspositori terhadap hasil belajar Pendidikan Kewarganegaraan (PKn) kelas XI IPS MAN Temanggung Semester Ganjil Tahun Pelajaran 2012/2013.

\section{KESIMPULAN}

Berdasarkan pada hasil penelitian yang dilakukan di MAN Temanggung pada mata pelajaran PKn, meteri tentang "Keterbukaan dan Keadilan" pada semester I tahun pelajaran 2012/ 2013 dan pada pembahasan di bab IV dapat disimpulkan sebagai berikut:"Ada perbedaan pengaruh yang signifikan antara pembelajaran kooperatif tipe Team-Games-Tournament (TGT) dan ekspositori terhadap hasil belajar PKn siswa yaitu hasil belajar yang menggunakan TGT lebih baik dibandingkan yang menggunakan pembelajaran ekspositori. “ 


\section{DAFTAR PUSTAKA}

Ahmad Haris Bhakti. 2009. Pengaruh Strategi Pembelajaran Kooperatif Tipe STAD dan Jigsaw Terhadap Prestasi Belajar Pendidikan Kewarganegaraan Ditinjau Dari Minat Belajar Siswa SMP Negeri di kecamatan Ngawi. Tesis. Surakarta: Program Studi Teknologi Pendidikan Program Pascasarjana Universitas Sebelas Maret Surakarta.

Dasim Budiansyah. 2007. Perkembangan kurikulum dan pembelajaran PKn. Jakarta: Universitas Terbuka.

Kiranawati. 2007. Pembelajaran Kooperatif Tipe Teams Games Tournament (TGT).http:// gurupkn.wordpress.com/2007/11/13/ metode-team-gamestournament-tgt/ (diunduh pada 20 Oktober 2012).

Nana Syaodih. 2007. Metode Penelitian Pendidikan. Bandung: Rosdakarya.

Nana Sudjana. 2010. Penilaian Hasil Proses Belajar Mengajar. Bandung: Remaja Rosdakarya.
Silvia Afritani. 2011. Perbedaan Prestasi Belajar Matematika Yang Diajar Dengan Metode Ekspositori Dan Discovery (Penemuan Terbimbing) Pada Materi Trigonometri Kelas X di SMA Laboratorium Kristen Satya Wacana. Salatiga: Tesis UKSW.

Slavin, Robert E. 2008. Cooperative Learning Teori, Riset dan Praktik. Bandung: Nusa Media.

Suryabrata, S. 2002. Proses Pembelajaran di Sekolah. Jakarta: Rineka Cipta.

Wina Sanjaya. 2012. Strategi Pembelajaran Berorientasi Standar Proses Pendidikan. Jakarta: Kencana Prenada Media Group.

Winarsi. 2008. Peningkatan Prestasi Belajar Siswa dalam Pembelajaran Matematika melalui Model Pembelajaran Kooperatif Learning tipe Teams-Games-Tournament (TGT) di Kelas V Sekolah Dasar Negeri 8 Pondok Kelapa. Jakarta: Skripsi UNIB 